\title{
Schizont
}

H. Baum

Institut für Laboratoriumsmedizin, Mikrobiologie und Blutdepot, Regionale Kliniken Holding RKH GmbH, Ludwigsburg, Deutschland

\section{Synonym(e) Meront}

\section{Englischer Begriff schizont}

Definition Ungeschlechtliche Teilungsform der Sporozoen mit mehreren Zellkernen.

Beschreibung Der Schizont ist die ungeschlechtliche Teilungsform von Sporozoen (z. B. der $>$ Plasmodien oder Toxoplasmen) im Zwischenwirt. Der Schizont besitzt mehrere Zellkerne. Nach dem Zerfall des mehrkernigen Schizonten werden einkernige Merozoiten freigesetzt, die wiederum neue Zellen befallen oder aber sich zu Gametozyten, den geschlechtlichen Formen differenzieren.

Die Abbildung zeigt einen intraerythrozytären Schizonten bei Malaria quartana $(1000 \times$, May-Giemsa-Grünwald-Färbung):

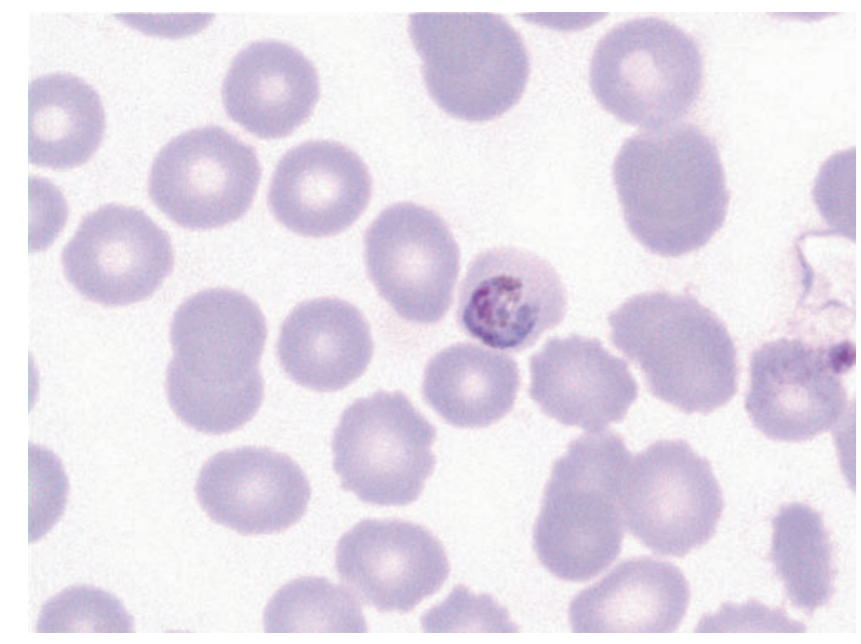

\section{Literatur}

Seitz HM, Maier W (1994) Parasitologie - Sporozoen. In: Brandis H, Köhler W, Eggers HJ et al (Hrsg) Lehrbuch der Medizinischen Mikrobiologie. Gustav Fischer Verlag, Stuttgart, S 654-667 